\title{
Novel Multilevel Inverter Carrier-Based PWM Method
}

\author{
Leon M. Tolbert, Senior Member, IEEE, and Thomas G. Habetler, Senior Member, IEEE
}

\begin{abstract}
The advent of the transformerless multilevel inverter topology has brought forth various pulsewidth modulation (PWM) schemes as a means to control the switching of the active devices in each of the multiple voltage levels in the inverter. An analysis of how existing multilevel carrier-based PWM affects switch utilization for the different levels of a diode-clamped inverter is conducted. Two novel carrier-based multilevel PWM schemes are presented which help to optimize or balance the switch utilization in multilevel inverters. A $10-\mathrm{kW}$ prototype sixlevel diode-clamped inverter has been built and controlled with the novel PWM strategies proposed in this paper to act as a voltage-source inverter for a motor drive.
\end{abstract}

Index Terms - Carrier-based pulsewidth modulation, diodeclamped inverter, multilevel converter, multilevel inverter, multilevel pulsewidth modulation.

\section{INTRODUCTION}

$\mathbf{M}$ ULTILEVEL pulsewidth modulation (PWM) inverters have been developed to overcome shortcomings in solid-state switching device ratings, so that large motors can be controlled by high-power adjustable-frequency drives. The most popular structure proposed as a transformerless voltagesource inverter is the diode-clamped converter based on the neutral-point converter proposed in [1]. A three-phase six-level diode-clamped inverter is shown in Fig. 1.

The two multilevel PWM methods most discussed in the literature are multilevel carrier-based PWM and multilevel space-vector PWM; both are extensions of traditional twolevel PWM strategies to several levels. Investigators have proposed carrier-based multilevel sine-triangle PWM schemes for control of a multilevel diode-clamped inverter used as a motor drive or static var compensator [2]-[9]. Others have generalized space-vector PWM theory for use with multilevel inverters [10]-[12]. A third PWM method used to control a multilevel diode-clamped converter is with selective harmonic elimination [13], [14].

While the multilevel PWM techniques developed thus far have been extensions of two-level PWM methods, the multiple levels in a diode-clamped inverter offer extra degrees of freedom and greater possibilities in terms of device utiliza-

Paper IPCSD 99-38, presented at the 1998 Industry Applications Society Annual Meeting, St. Louis, MO, October 12-16, and approved for publication in the IEEE TRANSACtions ON INDUSTRY APPLICATIONs by the Industrial Power Converter Committee of the IEEE Industry Applications Society. Manuscript released for publication March 18, 1999.

L. M. Tolbert is with Oak Ridge National Laboratory, Oak Ridge, TN 37831-8038 USA (e-mail: tolbertlm@ ornl.gov).

T. G. Habetler is with the School of Electrical and Computer Engineering, Georgia Institute of Technology, Atlanta, GA 30332-0250 USA (e-mail: tom.habetler@ece.gatech.edu).

Publisher Item Identifier S 0093-9994(99)05362-1.

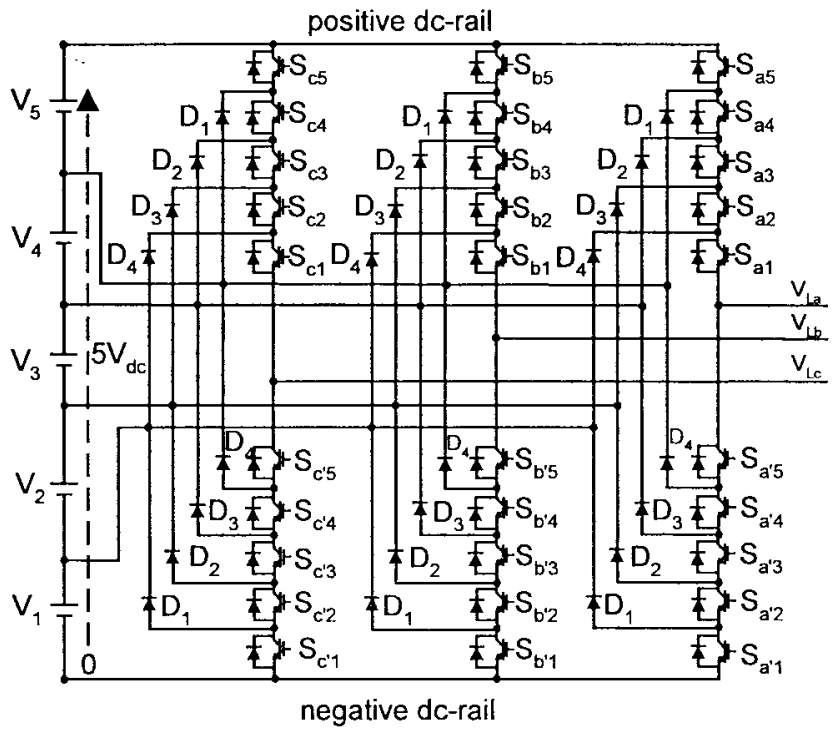

Fig. 1. Circuit diagram of a three-phase six-level diode-clamped inverter.

tion, state redundancies, and effective switching frequency. In this paper, novel carrier-based multilevel PWM schemes are presented which take advantage of the special properties available in multilevel inverters to minimize switch utilization and/or balance the switching duty among its various levels.

\section{Existing Multilevel CARrier-Based Methods}

\section{A. Subharmonic PWM Method}

Other authors have extended two-level carrier-based PWM techniques to multilevel inverters by making use of several triangular carrier signals and one reference signal per phase. Carrara [3] developed multilevel subharmonic PWM (SHPWM) as follows. For an $m$-level inverter, $m-1$ carriers with the same frequency $f_{c}$ and same peak-to-peak amplitude $A_{c}$ are disposed such that the bands they occupy are contiguous. The reference, or modulation, waveform has peak-to-peak amplitude $A_{m}$ and frequency $f_{m}$, and it is centered in the middle of the carrier set. The reference is continuously compared with each of the carrier signals. If the reference is greater than a carrier signal, then the active device corresponding to that carrier is switched on, and if the reference is less than a carrier signal, then the active device corresponding to that carrier is switched off. In multilevel inverters, the amplitude modulation 


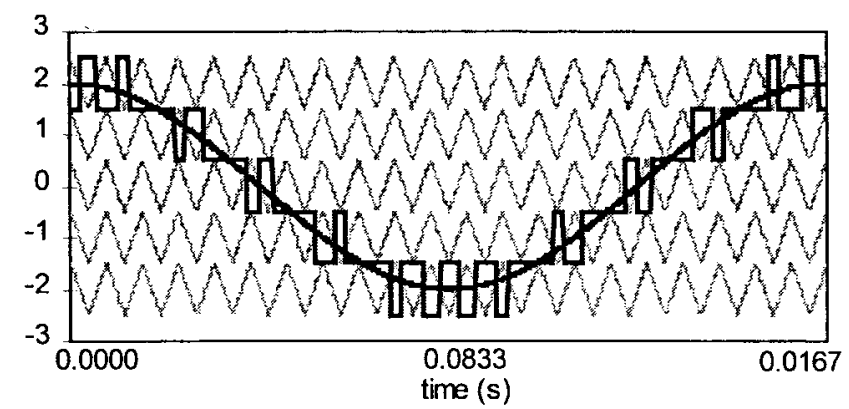

Fig. 2. Multilevel carrier-based SH-PWM showing carrier bands, modulation waveform, and inverter output waveform $\left(m=6, m_{f}=21\right.$, $\left.m_{a}=0.8\right)$.

index $m_{a}$ and the frequency ratio $m_{f}$ are defined as

$$
\begin{aligned}
& m_{a}=\frac{A_{m}}{(m-1) \cdot A_{c}}, \\
& m_{f}=\frac{f_{c}}{f_{m}} .
\end{aligned}
$$

Carrara also considered different methods of disposing the many carrier bands required in multilevel PWM. The three cases he considered for an inverter with an odd number of levels were as follows:

1) alternative phase opposition disposition, where each carrier band is shifted by $180^{\circ}$ from the adjacent bands;

2) phase opposition disposition, where the carriers above the zero reference are in phase, but shifted by $180^{\circ}$ from those carriers below the zero reference;

3) in-phase disposition, where all the carriers are in phase (further examination of in-phase disposition is given in this paper).

Fig. 2 shows a set of carriers $\left(m_{f}=21\right)$ with all of the carriers in phase for a six-level diode-clamped inverter and a sinusoidal reference voltage with $m_{a}=0.8$. The resulting output voltage of the inverter is also shown in Fig. 2.

\section{B. Switching-Frequency Optimal PWM Method}

Steinke [2] proposed a carrier-based method termed switching-frequency optimal PWM (SFO-PWM) which was similar to Carrara's, except that a zero-sequence (triplen harmonic) voltage is added to each of the carrier waveforms. This method takes the instantaneous average of the maximum and minimum of the three reference voltages $\left(V_{a}^{*}, V_{b}^{*}\right.$, and $V_{c}^{*}$ ) and subtracts this value from each of the individual reference voltages to obtain the modulation waveforms, i.e.,

$$
\begin{aligned}
V_{\text {offset }} & =\frac{\max \left(V_{a}^{*}, V_{b}^{*}, V_{c}^{*}\right)+\min \left(V_{a}^{*}, V_{b}^{*}, V_{c}^{*}\right)}{2} \\
V_{a}^{*} \text { SFO } & =V_{a}^{*}-V_{\text {offset }} \\
V_{b}^{*} \text { SFO } & =V_{b}^{*}-V_{\text {offset }} \\
V_{c \text { SFO }}^{*} & =V_{c}^{*}-V_{\text {offset. }}
\end{aligned}
$$

SFO-PWM is illustrated in Fig. 3 for the same reference voltage waveform that was used in Fig. 2. The resulting output

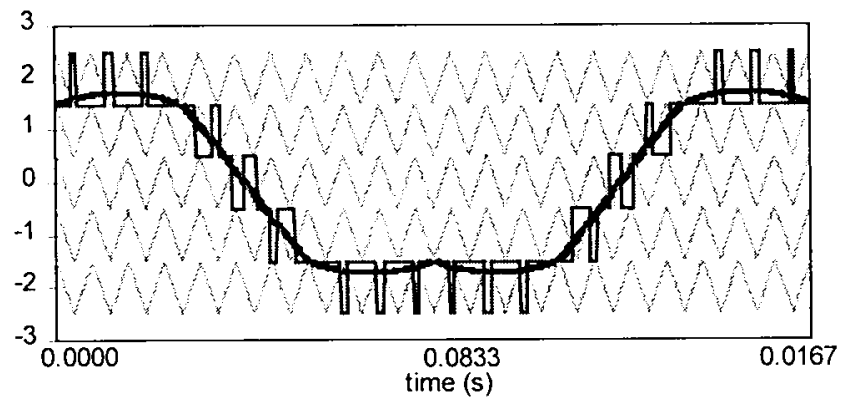

Fig. 3. Multilevel carrier-based SFO-PWM showing carrier bands, modulation waveform, and inverter output waveform $\left(m=6, m_{f}=21\right.$, $m_{a}=0.8$ ).

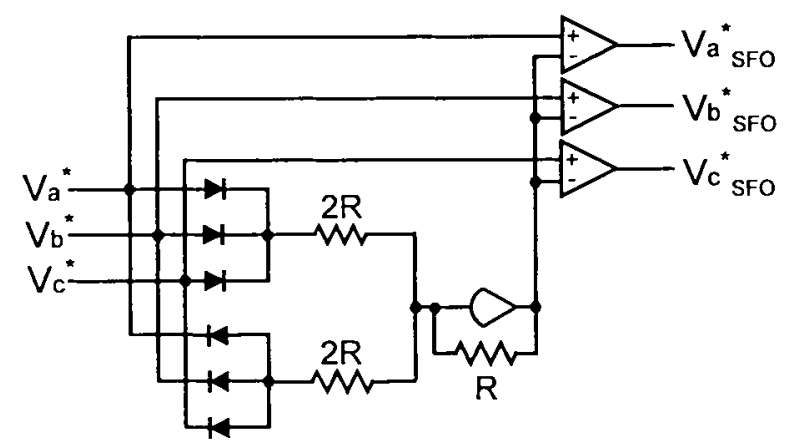

Fig. 4. Analog equivalent circuit for SFO-PWM zero-sequence addition.

voltage of the inverter is also shown in Fig. 3. The SFO-PWM technique can only be used for three-phase three-wire systems, and it enables the modulation index to be increased by $15 \%$ before overmodulation, or pulse dropping, occurs.

The addition of this triplen-offset voltage continuously centers all of the three reference waveforms in the carrier band, which Holmes [15] showed for carrier-based two-level PWM is similar to using space-vector PWM with the zero-voltage state divided evenly at the beginning and end of each half carrier interval. The analog equivalent of (3) and (4) is shown in Fig. 4 [16].

\section{Carrier Phase Angle EfFect on Switching}

Previously, Menzies [5] considered two simple cases of what effect the displacement phase angle $\phi$, between the modulation waveform (sinusoidal reference) and the set of carrier waveforms, has on the switching of the active devices and the unfiltered inverter output waveform distortion where

$$
V_{a}^{*}=|V| \cdot \cos (\theta-\phi) .
$$

The two cases considered were: 1) the carrier is a maximum when the reference is a maximum $(\phi=0)$, referred to as a Wtype carrier set and 2) the case where the carrier is a minimum when the reference is a maximum, referred to as an M-type carrier set.

In this paper, all displacement phase angles were considered. The displacement phase angle between the reference and carrier set was varied incrementally by $0.01 \mathrm{rad}$ from 0 to $2 \pi / 3 \mathrm{rad}\left(120^{\circ}\right)$ to see what effect this would have on the 


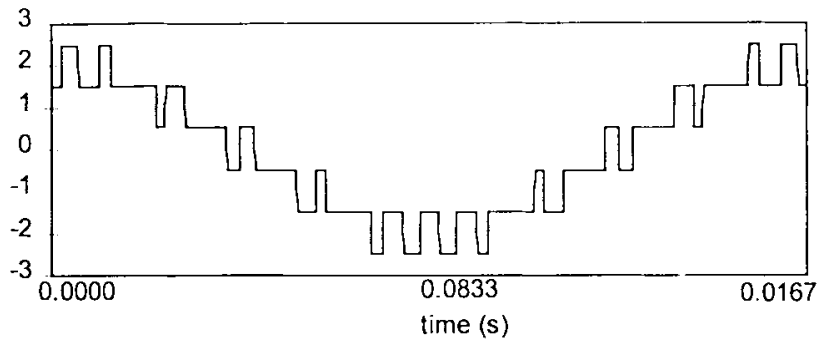

(a)

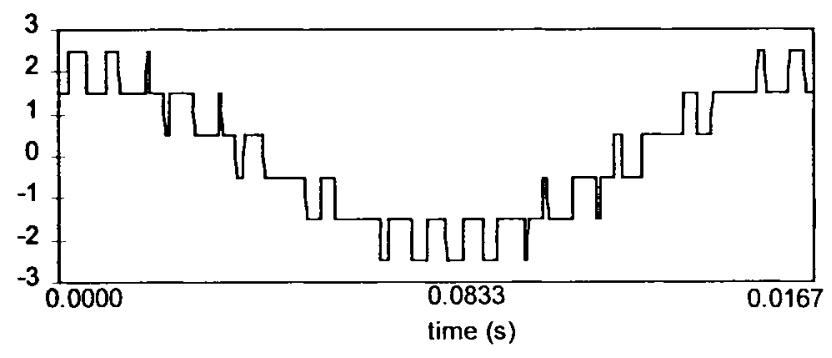

(c)

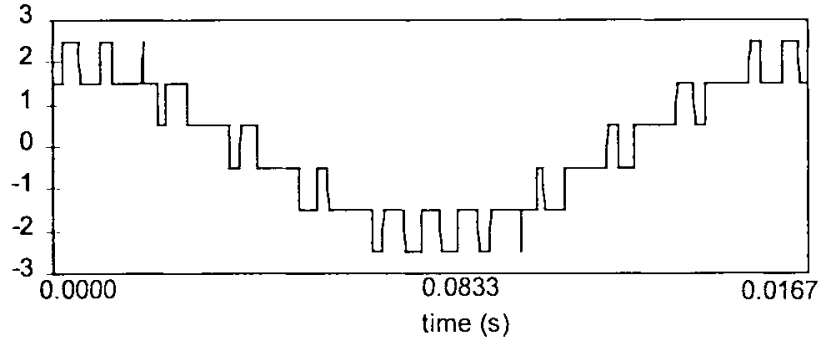

(b)

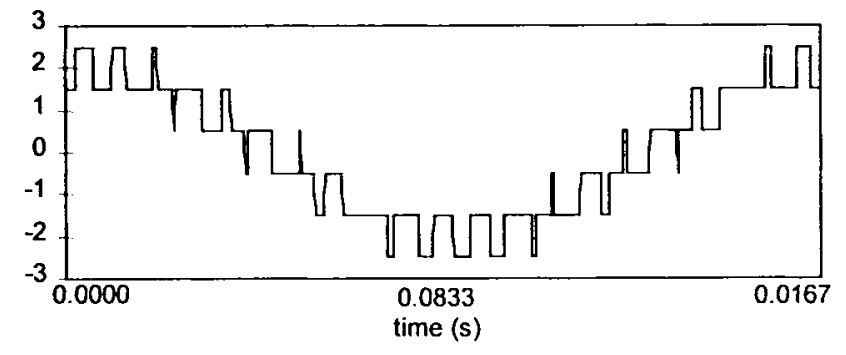

(d)

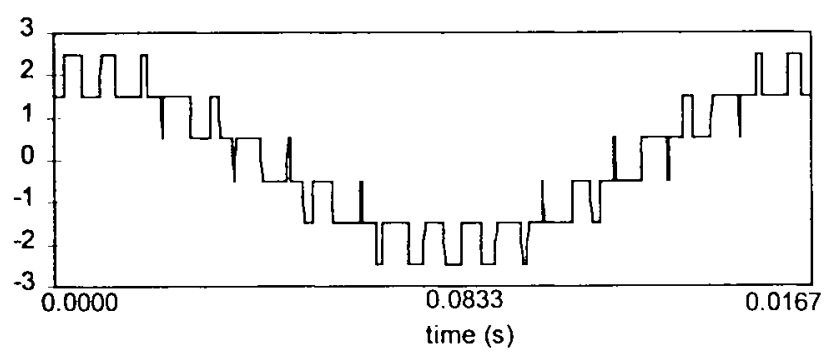

(e)

Fig. 5. Output voltage waveforms for a six-level inverter controlled with SH-PWM for various modulation displacement phase angles $\phi$. (a) SH-PWM, $m_{f}=21, m_{a}=0.8, \phi=0.00 \mathrm{rad}, N_{s w}=34$. (b) SH-PWM, $m_{f}=21, m_{a}=0.8, \phi=0.03 \mathrm{rad}, N_{s w}=38$. (c) SH-PWM, $m_{f}=21, m_{a}=0.8, \phi=0.08 \mathrm{rad}, N_{s w}=42$. (d) SH-PWM, $m_{f}=21, m_{a}=0.8, \phi=0.13 \mathrm{rad}, N_{s w}=46$. (e) SH-PWM, $m_{f}=21, m_{a}=0.8, \phi=0.15 \mathrm{rad}, N_{s w}=50$.

TABLE I

Number of Main Device Switchings in Each Level for Fig. 5 AND LINE-Line VOLTAGE THD FOR 3RD-19TH HARMONICS

\begin{tabular}{|c|c|c|c|c|c|c|c|}
\hline \multirow{2}{*}{$\begin{array}{c}\text { Phase } \\
\text { Angle, } \phi\end{array}$} & \multicolumn{6}{|c|}{ Switches/Cycle (SH-PWM, $m=6, m_{f}=21, m_{a}=0.8$ ) } & \multirow{2}{*}{$\begin{array}{l}\% V_{a b} \\
\text { THD }\end{array}$} \\
\hline & $S_{a l}$ & $S_{a 2}$ & $\overline{S_{a 3}}$ & $S_{a 4}$ & $S_{a 5}$ & $N_{s w}$ & \\
\hline $0.00 \mathrm{rad}$ & $\overline{8}$ & 6 & 6 & 6 & 8 & 34 & $5.37 \%$ \\
\hline $0.03 \mathrm{rad}$ & 10 & 6 & 6 & 6 & 10 & 38 & $5.77 \%$ \\
\hline $0.08 \mathrm{rad}$ & 10 & 8 & 6 & 8 & 10 & 42 & $5.34 \%$ \\
\hline $0.13 \mathrm{rad}$ & 10 & 8 & 10 & 8 & 10 & 46 & $5.37 \%$ \\
\hline $0.15 \mathrm{rad}$ & 10 & 10 & 10 & 10 & 10 & 50 & $5.27 \%$ \\
\hline
\end{tabular}

total switchings of the active devices and the output waveform distortion.

In Fig. 5, an example of controlling a six-level inverter with the SH-PWM method, with $m_{a}=0.8$ and $m_{f}=21$, shows that the total number of switchings (active device transition from on to off or off to on) $N_{s w}$ during a modulation cycle $1 / f_{m}$, can vary between $34-50$, depending on the phase angle of the reference. Although the waveforms are not quarter- wave symmetric for some values of $\phi$, the waveforms are always half-wave symmetric, regardless of the displacement angle. Note that, in a traditional two-level inverter with a single carrier wave, $N_{s w}=42$ for $m_{f}=21$, regardless of the displacement phase angle and for all values of $m_{a}<1$.

Table I shows the number of switchings at each level of the diode-clamped inverter for the examples shown in Fig. 5. The upper and lower main device pairs $\left(S_{a 1^{1}}-S_{a^{\prime} 1}, S_{a \check{5}}-S_{a^{\prime} 5}\right.$, in a six-level inverter), in general, are switched more often than the intermediate switches for carrier-based control, where each level has the same carrier frequency and all levels of the inverter are being used $\left(m_{a}>0.6\right.$ in a six-level inverter). Table I also shows the line-line voltage total harmonic distortion (THD) for the 3rd-19th harmonics for the examples shown in Fig. 5.

In Fig. 6, an example with a six-level inverter with the SFO-PWM method and the same parameters as Fig. 5 shows that the total number of switchings can vary between 30-46. Table II shows the number of switchings at each level of the inverter for the examples represented in Fig. 6. Again, and even more dramatically, the upper and lower main device 


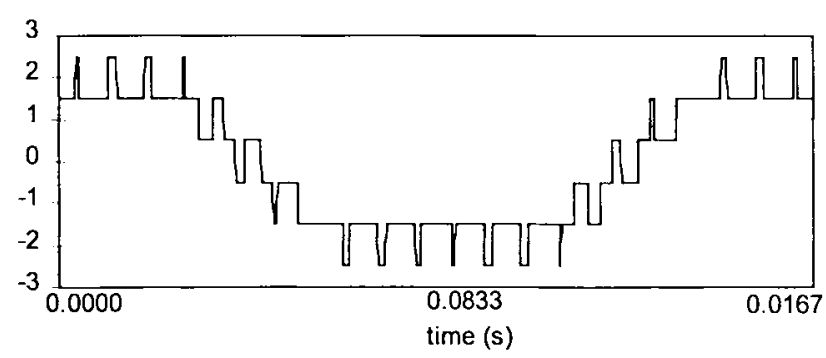

(a)

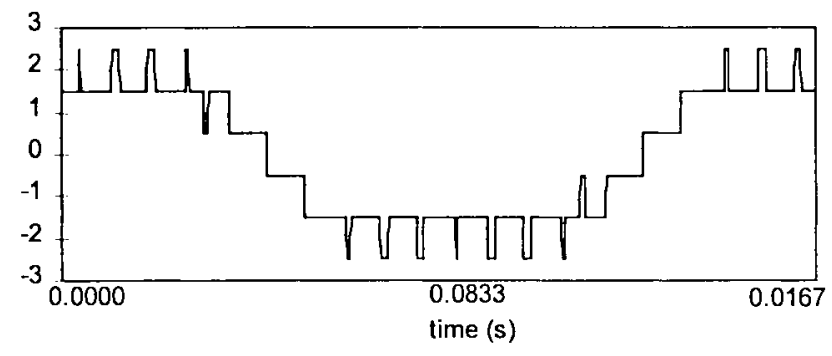

(c)

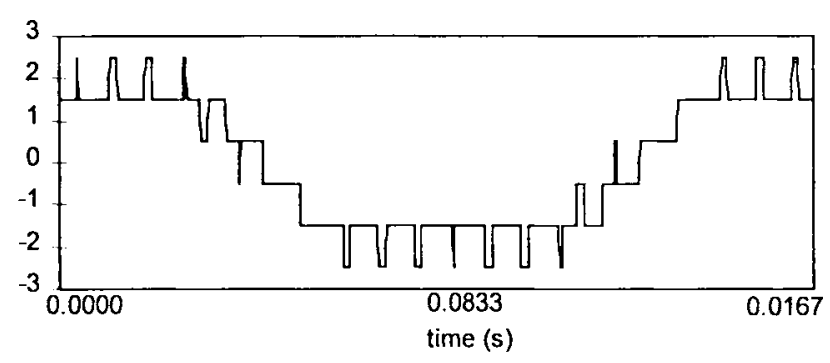

(b)

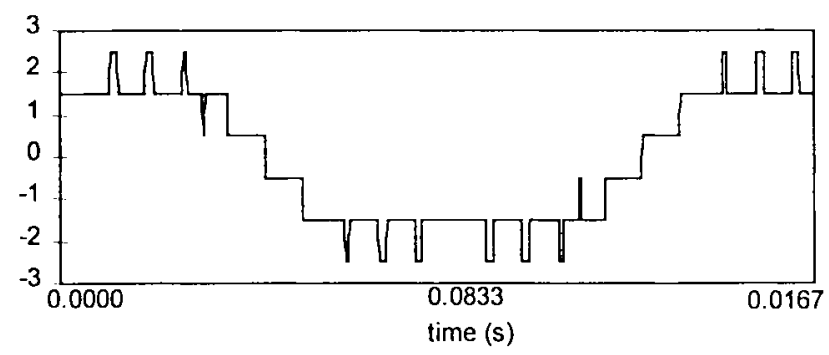

(d)

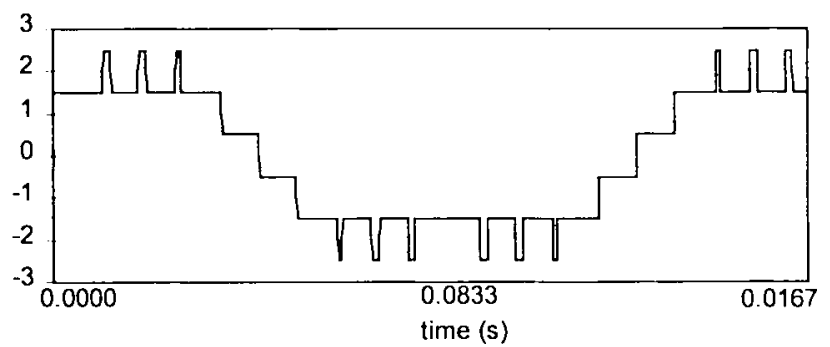

(e)

Fig. 6. Output voltage waveforms for a six-level inverter controlled with SFO-PWM for various modulation displacement phase angles $\phi$. (a) SFO-PWM, $m_{f}=21, m_{a}=0.8, \phi=0.03 \mathrm{rad}, N_{s w}=46$. (b) SFO-PWM, $m_{f}=21, m_{a}=0.8, \phi=0.08 \mathrm{rad}, N_{s w}=42$. (c) SFO-PWM, $m_{f}=21, m_{a}=0.8, \phi=0.11 \mathrm{rad}, N_{s w}=38$. (d) SFO-PWM, $m_{f}=21, m_{a}=0.8, \phi=0.13 \mathrm{rad}, N_{s w}=34$. (e) SFO-PWM, $m_{f}=21, m_{a}=0.8, \phi=0.15 \mathrm{rad}, N_{s w}=30$.

TABLE II

Number of Main Device Switchings in Each Level for Fig. 6 AND LiNE-Line Voltage THD FOR 3RD-19TH HARMONICS

\begin{tabular}{|c|c|c|c|c|c|c|c|}
\hline \multirow{2}{*}{$\begin{array}{c}\text { Phase } \\
\text { Angle, } \phi\end{array}$} & \multicolumn{6}{|c|}{ Switches/Cycle(SFO-PWM, $m=6, m_{f}=21, m_{a}=0.8$ ) } & \multirow{2}{*}{$\begin{array}{l}\% \mathrm{~V}_{\mathrm{ab}} \\
\text { THD }\end{array}$} \\
\hline & $S_{a l}$ & $S_{a 2}$ & $S_{a 3}$ & $S_{a 4}$ & $S_{a s}$ & $N_{s w}$ & \\
\hline $0.03 \mathrm{rad}$ & 14 & 6 & 6 & 6 & 14 & 46 & $4.05 \%$ \\
\hline $0.08 \mathrm{rad}$ & 14 & 4 & 6 & 4 & 14 & 42 & $3.94 \%$ \\
\hline $0.11 \mathrm{rad}$ & 14 & 4 & 2 & 4 & 14 & 38 & $3.70 \%$ \\
\hline $0.13 \mathrm{rad}$ & 12 & 4 & 2 & 4 & 12 & 34 & $3.41 \%$ \\
\hline $0.15 \mathrm{rad}$ & 12 & 2 & 2 & 2 & 12 & 30 & $2.92 \%$ \\
\hline
\end{tabular}

pairs are switched more often than the intermediate switches. Table II also shows the line-line voltage THD for the 3rd-19th harmonics for the examples shown in Fig. 6.

Fig. 7 shows the frequency spectrum for the unfiltered output phase voltage shown in Fig. 5(a) $(\phi=0.00 \mathrm{rad}$, $\left.N_{s w}=34\right)$ and Fig. 5(e) $\left(\phi=0.15 \mathrm{rad}, N_{s w}=50\right)$. From these frequency spectrums, one can see that the dominant harmonic in the phase voltage $(21 \mathrm{st})$ is the carrier ratio $m_{f}$. The frequency spectrums for line-line voltages are also shown in Fig. 7. One should note that no harmonic component exists at the carrier ratio in the line-line voltage.

One can also see that the only difference in the frequency spectrum for the two different displacement angles is in the magnitude of the harmonics, the order of which is above the carrier ratio $\left(m_{f}=21\right)$. The magnitude of the harmonics, the order of which is below the carrier ratio, is nearly identical for the two cases.

An algorithm was written to count the total number of switchings during a modulation cycle with varying values of $\phi$ for $m_{f}$ from 9 to 39 for the SH-PWM and SFO-PWM cases for values of $m_{a}$ between $0.05-1.35$ and for $m=6$. Some interesting observations have been gleaned from these simulations.

1) If the carrier ratio $m_{f}$ is a multiple of 16 , the phase angle between the carrier and reference generally has no effect on the total number of switchings, i.e., $N_{s w}$ does not vary with $\phi\left(N_{s w}=2 m_{f}\right.$ for this case).

2) If the carrier ratio $m_{f}$ is even (multiple of 2), then the maximum number of switchings for a modulation cycle 


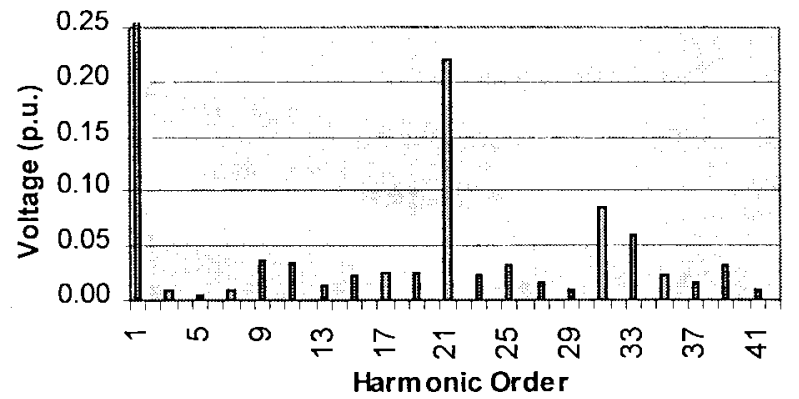

(a)

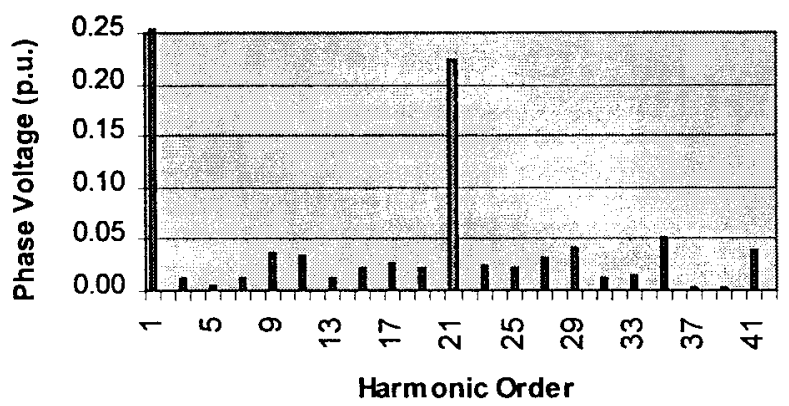

(c)

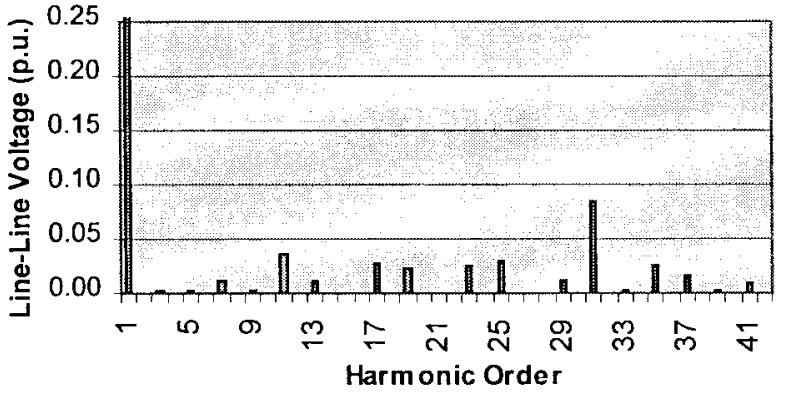

(b)

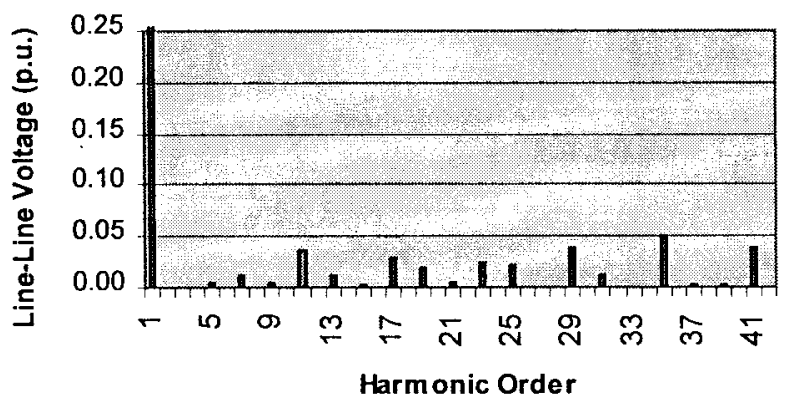

(d)

Fig. 7. Frequency spectrum of unfiltered output phase and line-line voltage waveforms: (a) from Fig. 5(a) and (c) from Fig. 5(e). (a) $V_{a n}$, SH-PWM, $m_{f}=21, m_{a}=0.8, \phi=0.00 \mathrm{rad}, N_{s w}=34$. (b) $V_{a b}$, SH-PWM, $m_{f}=21, m_{a}=0.8, \phi=0.00 \mathrm{rad}, N_{s w}=34$. (c) $V_{a n}$, SH-PWM, $m_{f}=21, m_{a}=0.8, \phi=0.15 \mathrm{rad}, N_{s w}=50$. (d) $V_{a b}$, SH-PWM, $m_{f}=21, m_{a}=0.8, \phi=0.15 \mathrm{rad}, N_{s w}=50$.

is $2 m_{f}$ and $N_{s w}=2 m_{f}-2 j$ where $j=0,1,2,3$ (exact values for $j$ depend on $m_{a}$ and the carrier ratio $\left.m_{f}\right)$.

3) If the carrier ratio $m_{f}$ is odd, then the maximum number of switchings for a modulation cycle is greater than $2 m_{f}$ and $N_{s w}=2 m_{f}+4 j$ where $j=-2,-1,0,1,2$ (exact values for $j$ depend on $m_{a}$ and the carrier ratio $m_{f}$ ).

4) The number of switchings per modulation cycle is a function of the amplitude modulation index, the carrier ratio, and the displacement phase angle. At lower amplitude modulation indexes $\left(m_{a}<0.6\right.$ in a six-level inverter with SH-PWM), some levels go unused [18].

These points show a major difference between two-level PWM and multilevel PWM. In two-level PWM, the switching frequency is always equal to the carrier frequency for modulation indexes less than unity. In multilevel PWM, the switching frequency can be less than or greater than the carrier frequency and is a function of the displacement angle between the carrier set and the modulation waveform. By choosing a phase displacement angle that minimizes the number of active device switchings for a particular $m_{a}$ and $m_{f}$, switching losses can be reduced by as much as $35 \%$, which increases the efficiency of the inverter considerably.

Another possible phase-shifting method not yet explored is to shift each of the carrier bands relative to one another instead of shifting the whole carrier band set relative to the modulation waveform.

\section{VARIABLE-Frequency CARRIER BANDS}

A method that could control or at least predict the number of switchings that occur at each level in a multilevel inverter

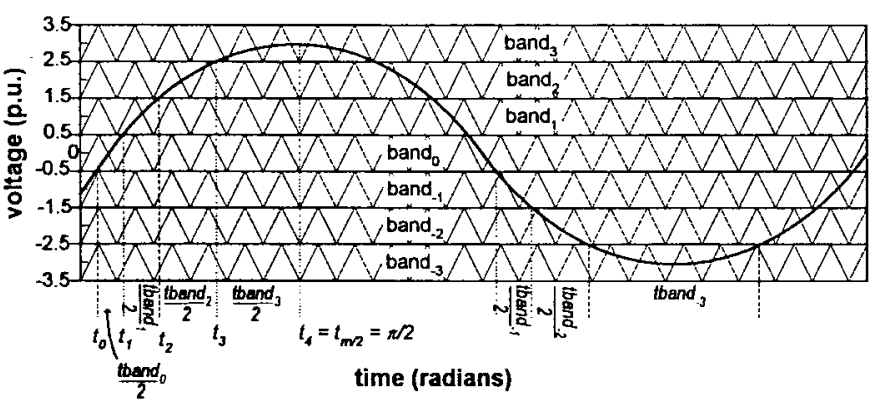

(a)

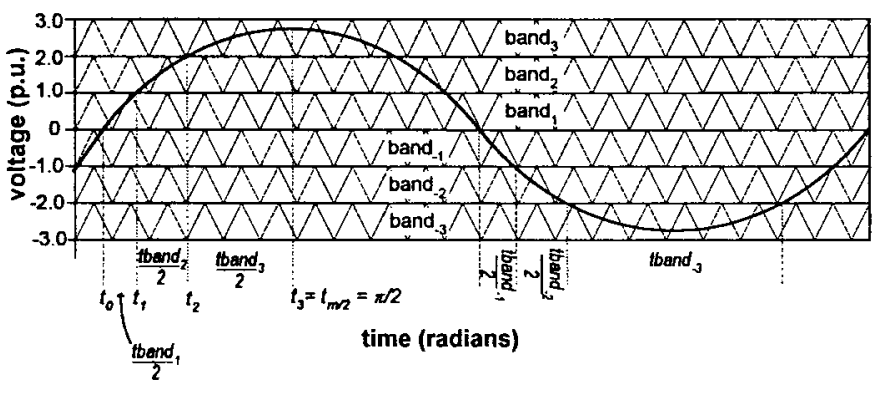

(b)

Fig. 8. SH-PWM reference dwell times for individual carrier bands. (a) Odd number of carrier time bands ( $m$ is even). (b) Even number of carrier time bands ( $m$ is odd).

would be advantageous. To accomplish this objective in a multilevel voltage-source inverter that has a sine-wave reference, knowledge of how long the reference dwells in each of the 


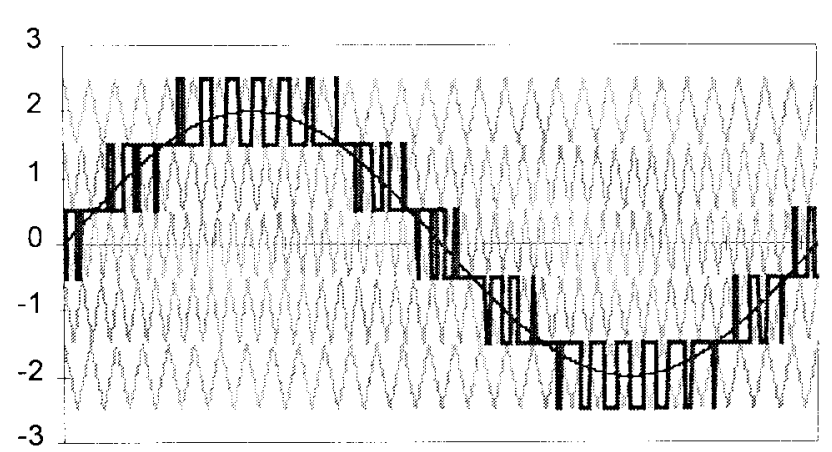

(a)

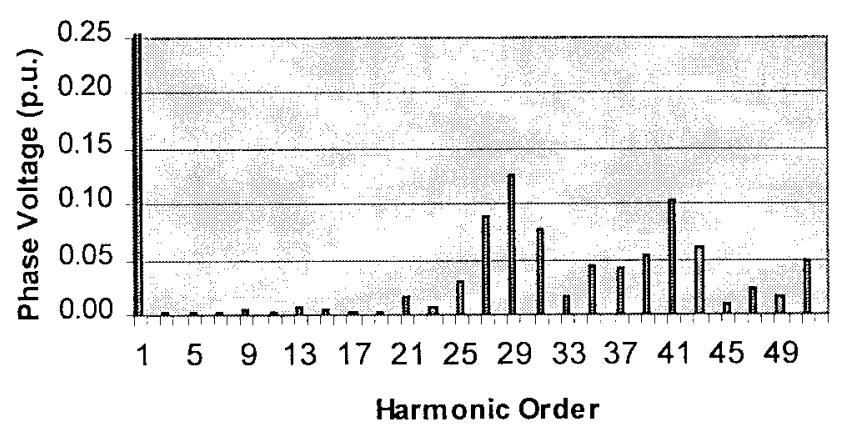

(b)

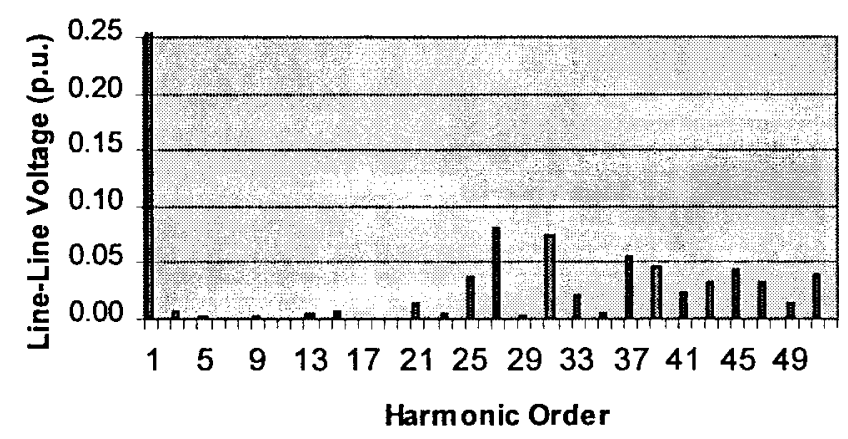

(c)

Fig. 9. SH-PWM where carriers have different frequencies $\left(m_{f}=29 \text { for Band } 2 \text {, Band }-2 ; m_{f}=41 \text { for Band } 1 \text {, Band }-1 ; m_{f}=49 \text { for Band }\right)_{0}$. (a) Carriers, reference, and inverter phase voltage waveform. (b) Phase voltage harmonic spectrum. (c) Line-line voltage harmonic spectrum.

carrier time bands is required. The following section details how this information is obtained.

\section{A. SH-PWM}

In carrier-based multilevel PWM, the number of carrier bands is one less than the number of voltage levels $m$ as shown in Fig. 8(a) for an inverter with an odd number of bands (even number of levels) and in Fig. 8(b) for an inverter with an even number of bands (odd number of levels). For a sine-wave modulation (reference) waveform centered in the carrier bands (SH-PWM), the duration of time that the waveform exists during each of the bands occupied can be computed as follows. Using the amplitude symmetry of the sine wave about the time axis, the band crossing times $t_{n}$, where the reference waveform crosses from one band to an adjacent band, for bands above (or containing the zero axis in the case that $m$ is even) can be computed from

$$
\begin{aligned}
& t_{n}=\arcsin \left(\frac{2 \cdot n-\bmod \left(\frac{m-1}{2}\right)}{m_{a} \cdot(m-1)}\right), \\
& n=0,1,2, \cdots\left\lfloor\frac{m}{2}-1\right\rfloor
\end{aligned}
$$

where $\bmod (x / y)$ is the modulus operator. Also noting that the sine wave has a maximum amplitude at $\pi / 2$, this is set equal to $t_{\lfloor m / 2\rfloor}$. From (6), the band dwell times in radians (starting at the band adjacent to the zero axis in the case that $m$ is odd or the band occupying the zero axis in the case that $m$ is even) are then calculated

$$
\begin{aligned}
& \text { tband }_{n}=2 \cdot\left(t_{n+1}-t_{n}\right), \\
& \qquad \text { where } n=0,1,2, \cdots\left\lfloor\frac{m}{2}-1\right\rfloor .
\end{aligned}
$$

Because of the symmetry of the sine wave about the zero axis, the bands below the zero axis are simply

$$
\text { tband }_{-n}=\text { tband }_{n} \text {. }
$$

The number of switchings per modulation cycle at each level of the inverter is dependent on the carrier frequency for that level and the duration of time that the reference waveform dwells within the level's corresponding time band. If the carrier frequency for all of the levels is identical, the top and bottom levels will have many more switchings than the intermediate levels, as shown in the previous section.

One method to balance the number of active switchings among the levels is to vary the carrier frequency of each band based on the time duration that the reference waveform dwells during the time band. The relationship between the number of switchings per band, $N_{s w n}$, and the frequency ratio, $m_{f n}$, for each band $n$ of an inverter is approximately given as follows:

$$
m_{f_{n}}=\frac{\pi \cdot N_{s w_{n}}}{\operatorname{tband}_{n}}=\frac{\pi \cdot N_{s w_{n 2}}}{2 \cdot\left(t_{n+1}-t_{n}\right)} .
$$




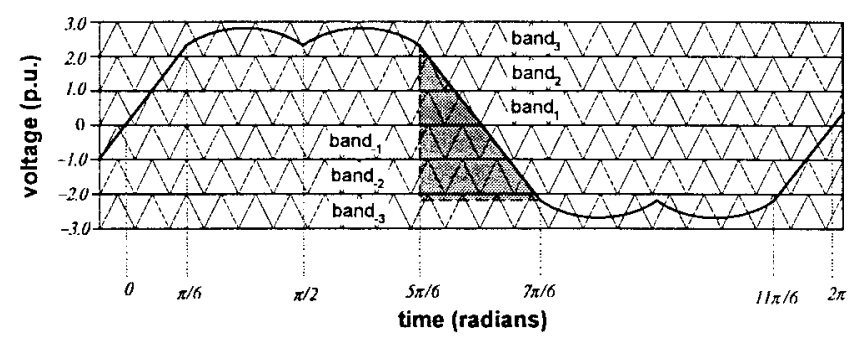

(a)

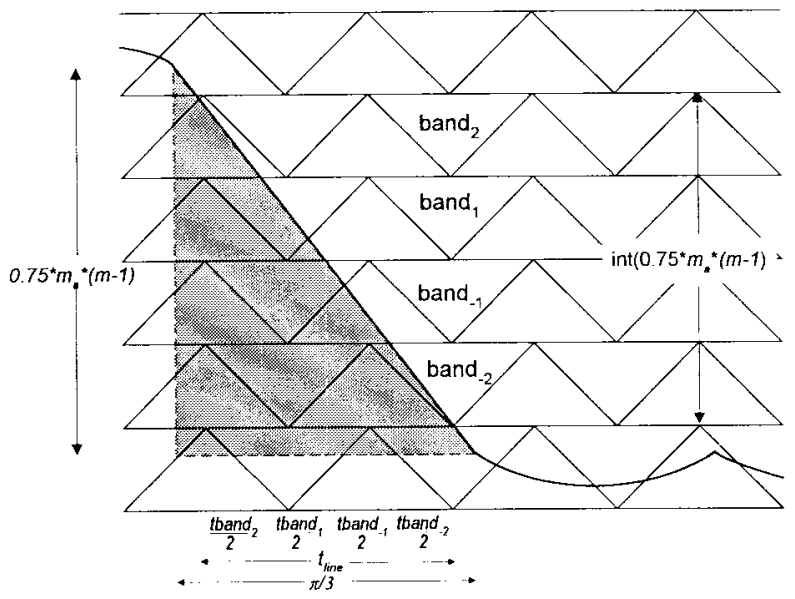

(b)

Fig. 10. Carrier bands for a seven-level inverter with SFO-PWM. (a) Modulation waveform and carrier bands. (b) Expanded view of straight segment.

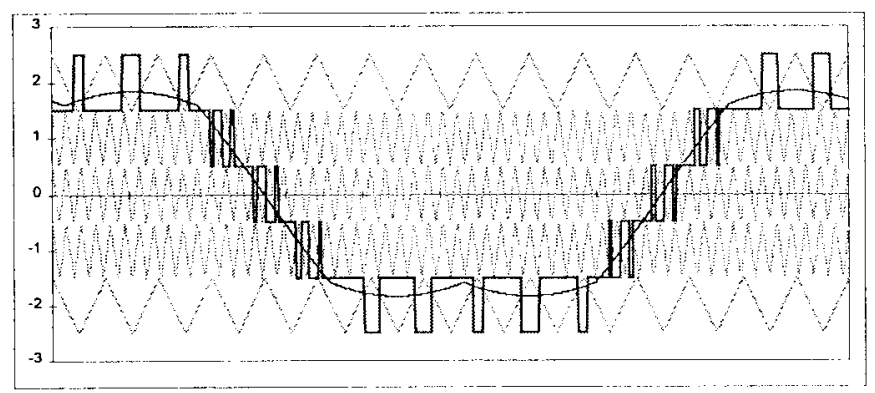

Fig. 11. SFO-PWM where carriers have different frequencies $\left(m_{a}=0.85\right.$, $m_{f}=15$ for top and bottom bands, $m_{f}=55$ for intermediate bands, $\phi=0.10)$.

From (9) and solutions to (7) and (8), the frequency ratio $m_{f_{n i}}$ for each band can be set such that each of the levels in the inverter has approximately the same number of active device switchings per cycle, i.e., $N_{s w_{n}}$ is the same for all levels. Fig. 9 shows an example of the carrier waves and resulting output phase voltage from this control where $N_{s w_{n}}$ has been set to 14. Harmonic spectra for the phase voltage and line-line voltage are also shown in Fig. 9.

\section{B. SFO-PWM}

To control the number of switchings in a multilevel inverter that is using SFO-PWM, different equations are needed

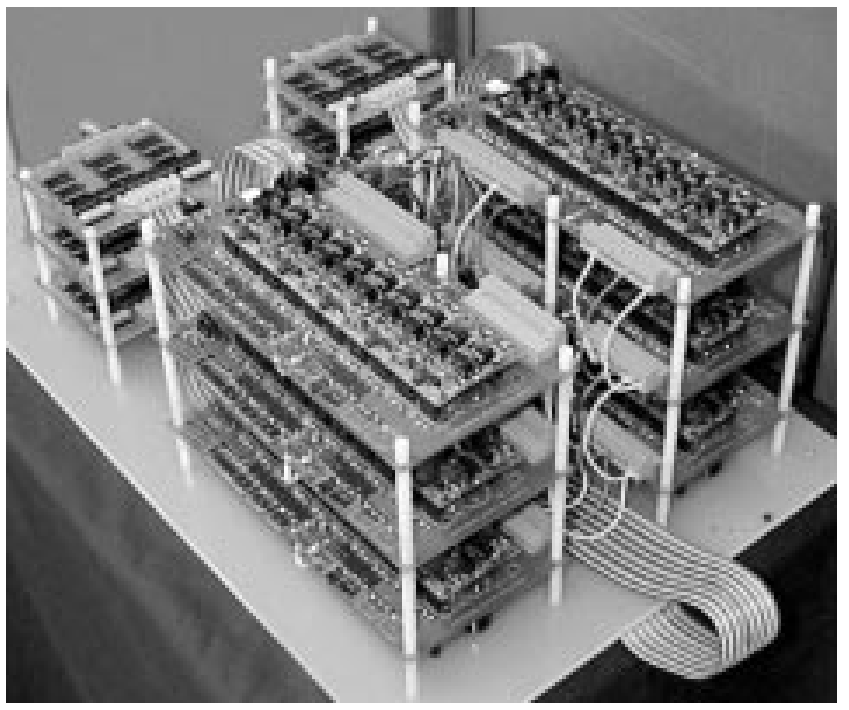

Fig. 12. Prototype six-level 10-kW back-to-back diode-clamped converter.

to calculate the time duration that a sine-wave reference waveform with zero-sequence addition dwells in each band. Fig. 10(a) shows the carrier bands and reference waveform for multilevel SFO-PWM control. From this figure, one can see that the modulation waveform contains two segments that can be closely approximated as straight lines. Each of these line segments has a horizontal time duration of $\pi / 3 \mathrm{rad}$ and a vertical amplitude of $0.75 \cdot m_{a} \cdot(m-1)$. Using the properties of proportional triangles from the enlarged area shown in Fig. 10(b), the following equations result:

$$
\frac{t_{\text {line }}}{\pi / 3}=\frac{\operatorname{int}\left(0.75 \cdot m_{a} \cdot(m-1)\right)}{0.75 \cdot m_{a} \cdot(m-1)}
$$

and

$$
\operatorname{tband}_{n}=\text { tband }_{-n}=\frac{t_{\text {line }}}{\operatorname{int}\left(0.75 \cdot m_{a} \cdot(m-1)\right)}
$$

where

$$
n=0,1,2, \cdots,\left\lfloor\operatorname{int}\left(0.75 \cdot m_{a} \cdot(m-1)\right) / 2\right\rfloor .
$$

The two "humps" at the top and bottom of the SFOPWM modulation waveform each have a time duration of $2 \pi / 3 \mathrm{rad}$. Considering the case where the two humps are wholly contained within a time band, the time duration that the modulation waveform dwells within these two bands can be given as

$$
\text { tband }_{n+1}=\text { tband }_{-(n+1)}=\frac{2 \pi}{3}+\frac{1}{2}\left(\frac{\pi}{3}-t_{\text {line }}\right)
$$

where $n$ is the maximum value used in (11).

Once the duration of dwell time for each of the carrier bands is known, (9) can be used to balance the number of switchings per modulation cycle among the levels of the inverter.

Fig. 11 shows SFO-PWM where carriers have different frequencies for the intermediate bands $\left(m_{f}=53\right)$ and the 


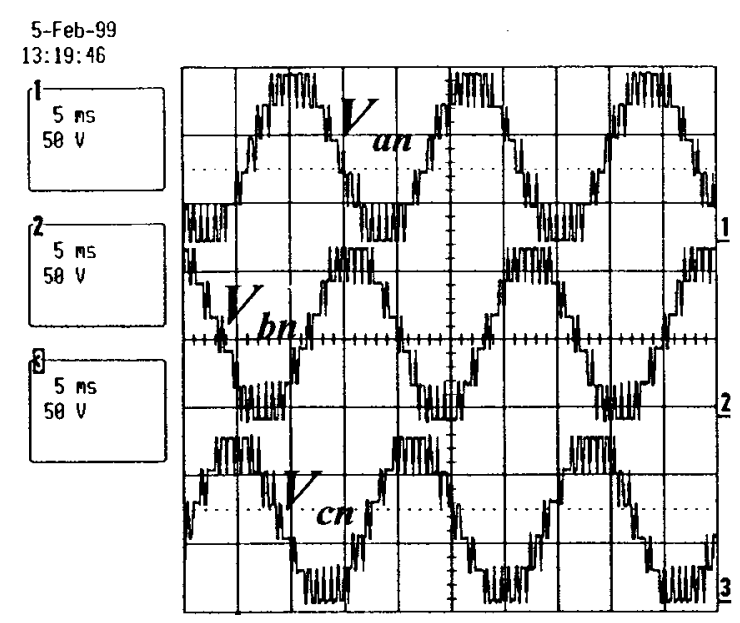

(a)

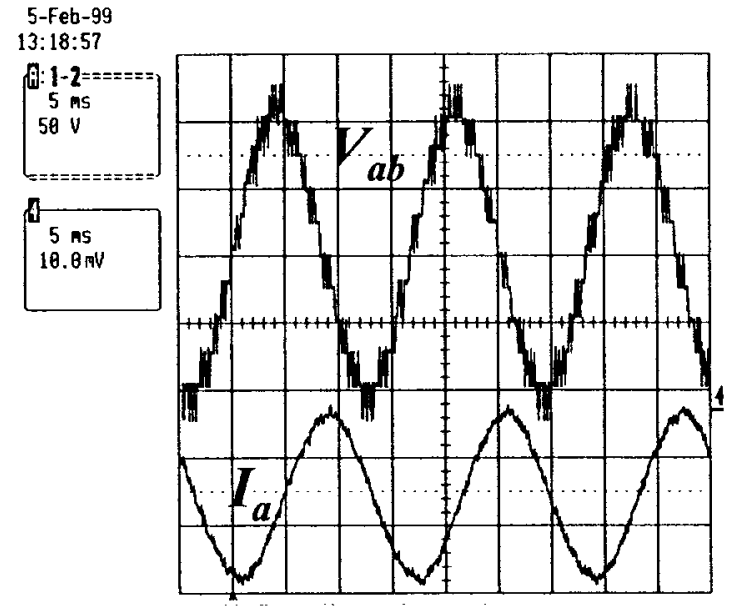

(b)

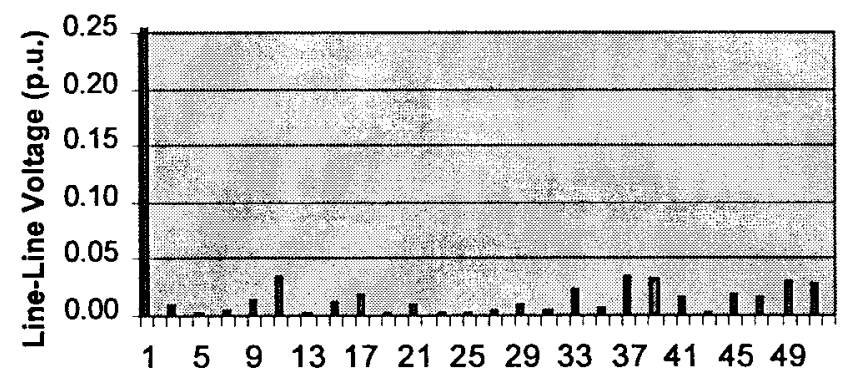

Harmonic Order

(c)

Fig. 13. Experimental voltage and current waveforms for multilevel converter controlled with same-frequency carrier bands. (SH-PWM, $m_{a}=0.95, \phi=0.02 \mathrm{rad}, m_{f}=25$ for all bands). (a) Line-neutral voltages $V_{a n}, V_{b n}$, and $V_{c n}$. (b) Line-line voltage $V_{a b}$ and current $I_{a}$. (c) Harmonic spectrum for line-line voltage, $V_{a b}$.

top and bottom bands $\left(m_{f}=11\right)$, so that each level has 12 switchings per cycle. This example illustrates that balancing the switchings at each level of the inverter when using SFOPWM requires a large difference between the frequency of the carrier bands that contain the two humps and the frequency of the carrier bands that intercept only the straight-line portion of the modulation waveform.

\section{HARDWARE IMPLEMENTATION}

A six-level three-phase back-to-back $10-\mathrm{kW}$ converter prototype, pictured in Fig. 12, has been built for operation at a line voltage of $208 \mathrm{~V}$ for use as an adjustable-speed drive for an induction motor [17], [18]. The active switching devices used for the converter were 100-V 100-A MOSFET's. Each internal dc level of the converter had a capacitance of $6.72 \mathrm{mF}$.

A table of switching patterns, which correspond to different amplitude modulation indexes and can be optimized for the fewest switches per cycle by determining the phase displacement angle to use at each amplitude modulation index, was calculated off-line and stored in a digital signal processor controller as 1024 states per cycle. A constant voltage/frequency control technique was applied to the motor drive system. As a user interface, a potentiometer was adjusted to apply an external $0-3-\mathrm{V}$ signal to the controller. The $0-3-\mathrm{V}$ signal mapped directly to a $0-60-\mathrm{Hz}$ fundamental frequency for the gate signals sent to the inverter. Also, the switching patterns corresponding to the various modulation indexes were mapped from the $0-3-\mathrm{V}$ external control signal.

The inverter was used to drive a 3/4-hp induction motor and was first controlled with SH-PWM with the following parameters: $m_{a}=0.95, m_{f}=25$, and $\phi=0.02 \mathrm{rad}$. The inverter's output line-neutral voltage waveforms for all three phases are shown in Fig. 13(a), and the line-line voltage waveform $V_{a b}$ and current waveform $I_{a}$ are shown in Fig. 13(b). From the line-neutral waveforms, one can see that the top and bottom active devices in each phase switch 14 times per modulation cycle, whereas the intermediate devices only switch six times per modulation cycle.

The prototype inverter was also controlled using carrier bands with different carrier frequencies, as discussed in Section IV. Specifically, the top and bottom bands had a frequency index of 17, while the next innermost bands had a frequency index of 37 , and the center band had a frequency index of 43. The amplitude modulation index $m_{a}=0.95$, and $\phi=0.00$ for this example. Fig. 14 shows the inverter's output line-neutral and line-line voltage waveforms and current waveform when using this type of control method. All of the active devices in the inverter switch states either eight or ten times per modulation cycle. 


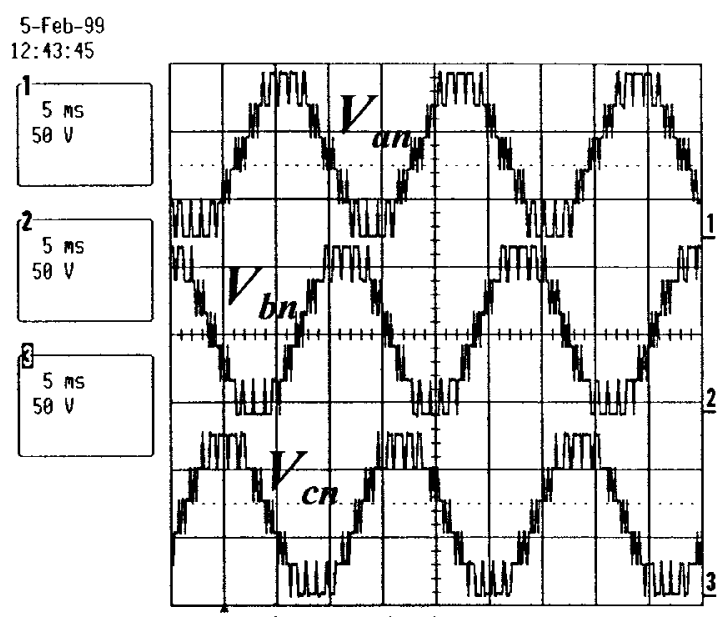

(a)

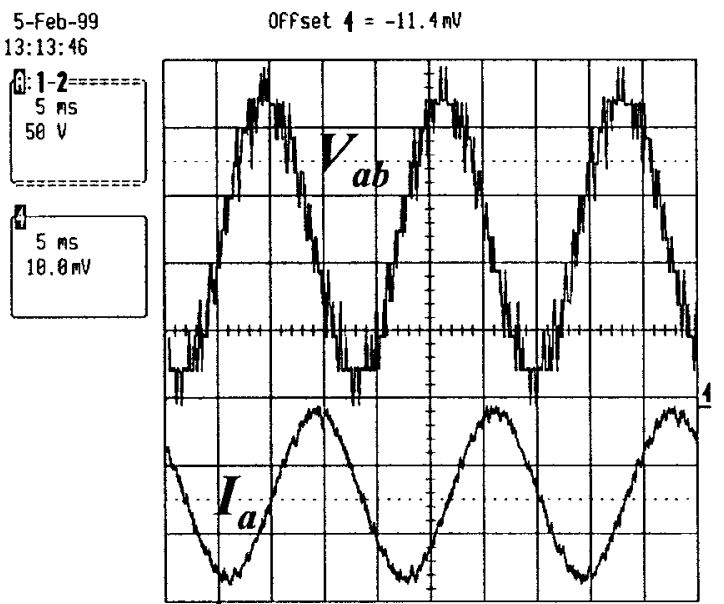

(b)

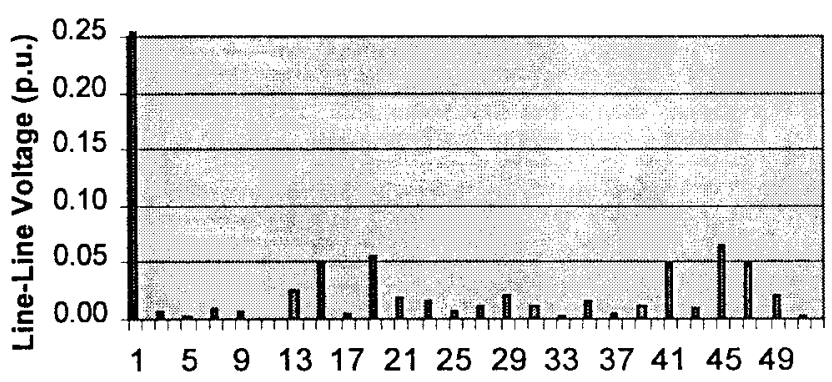

Harmonic Order

(c)

Fig. 14. Experimental voltage and current waveforms for multilevel converter controlled with variable-frequency carrier bands. (SH-PWM, $m_{a}=0.95, \phi=0.00 \mathrm{rad}, m_{f}=17$ for top and bottom bands, $m_{f}=37$ for intermediate bands, $m_{f}=43$ for center band). (a) Line-neutral voltages $V_{a n}, V_{b n}$, and $V_{c n}$. (b) Line-line voltage $V_{a b}$ and current $I_{a}$. (c) Harmonic spectrum for line-line voltage, $V_{a b}$.

The THD of the line-line voltage waveform in Fig. 13(b) is $4.6 \%$, and no individual harmonic component has a magnitude greater than $3.4 \%$ of the fundamental. The THD for the 3rd through 29th harmonic of the line-line voltage waveform in Fig. 14(b) is $8.8 \%$. From the harmonic spectrum shown in Fig. 14(c), the dominant harmonics (15th at 5.2\% and 19th at $5.4 \%$ ) are adjacent to the frequency index of 17.

For this particular example, the control scheme balanced the number of device switchings, but slightly increased the distortion in the inverter's output voltage. However, because a sinusoidal line-line voltage is the desired waveform for most motor drives, an algorithm can be written to determine $a$ priori the minimum harmonic distortion for a given amplitude modulation index and desired switch utilization by combining the procedures outlined previously in Sections III and IV.

\section{CONCLUSION}

Multilevel carrier-based PWM offers many more degrees of freedom than traditional two-level PWM. In multilevel PWM, the switching frequency can be less than or greater than the carrier frequency and is a function of the displacement phase angle between the carrier set and the modulation waveform. By adjusting the displacement phase angle in multilevel PWM switching strategies, switching losses can be minimized for a more efficient multilevel inverter.

In traditional subharmonic PWM and switching-frequency optimal PWM, the top and bottom switches are switched much more often than the intermediate devices. A novel method to balance device switchings for all of the levels in a diodeclamped inverter has been demonstrated for SH-PWM and SFO-PWM by varying the frequency for the different trianglewave carrier bands.

A six-level back-to-back diode-clamped converter prototype has established that these novel carrier-based switching strategies can be used to enable better switch utilization. The need for an algorithm to combine the two procedures studied (changing the phase displacement angle and varying the frequency of the carrier bands) has been identified.

\section{REFERENCES}

[1] A. Nabae, I. Takahashi, and H. Akagi, "A new neutral-point-clamped PWM inverter," IEEE Trans. Ind. Applicat., vol. IA-17, pp. 518-523, Sept./Oct. 1981.

[2] J. K. Steinke, "Control strategy for a three phase ac traction drive with a 3-level GTO PWM inverter," in Proc. IEEE PESC'88, 1988, pp. 431-438.

[3] G. Carrara, S. Gardella, M. Mar.esoni, R. Salutari, and G. Sciutto, "A new multilevel PWM method: A theoretical analysis," IEEE Trans. Power Electron., vol. 7, pp. 497-505, July 1992. 
[4] R. W. Menzies, P. Steimer, and J. K. Steinke, "Five-level GTO inverters for large induction motor drives," IEEE Trans. Ind. Applicat., vol. 30, pp. 938-944, July/Aug. 1994.

[5] R. W. Menzies and Y. Zhuang, "Advanced static compensation using a multilevel GTO thyristor inverter," IEEE Trans. Power Delivery, vol. 10, pp. 732-738, Apr. 1995.

[6] Y. Chen, B. Mwinyiwiwa, Z. Wolanski, and B. T. Ooi, "Regulating and equalizing DC capacitance voltages in multilevel STATCOM," IEEE Trans. Power Delivery, vol. 12, pp. 901-907, Apr. 1997.

[7] N. S. Choi, J. G. Cho, and G. H. Cho, "A general circuit topology of multilevel inverter," in Proc. IEEE PESC'91, 1991, pp. 96-103.

[8] N. S. Choi, G. C. Cho, and G. H. Cho, "Modeling and analysis of a static var compensator using multilevel voltage source inverter," in Conf. Rec. IEEE-IAS Annu. Meeting, 1993, pp. 901-908.

[9] V. G. Agelidis and M. Calais, "Application specific harmonic performance evaluation of multicarrier PWM Techniques," in Proc. IEEE PESC'98, 1998, pp. 172-178.

[10] M. Fracchia, T. Ghiara, M. Marchesoni, and M. Mazzucchelli, "Optimized modulation techniques for the generalized $N$-level converter," in Proc. IEEE PESC'92, 1992, pp. 1205-1213.

[11] H. L. Liu and G. H. Cho, "Three-level space vector PWM in low index modulation region avoiding narrow pulse problem," IEEE Trans. Power Electron., vol. 9, pp. 481-486, Sept. 1994.

[12] G. Sinha and T. A. Lipo, "A four level rectifier-inverter system for drive applications," in Conf. Rec. IEEE-IAS Annu. Meeting, 1996, pp. 980-987.

[13] M. H. Ohsato, G. Kimura, and M. Shioya, "Five-stepped PWM inverter used in photovoltaic systems," IEEE Trans. Ind. Electron., vol. 38, pp. 393-397, Oct. 1991.
[14] G. Carrara, D. Casini, S. Gardella, and R. Salutari, "Optimal PWM for the control of multilevel voltage source inverter," in Proc. 5th Annu. Eur. Conf. Power Electronics, 1993, vol. 4, pp. 255-259.

[15] D. G. Holmes, "The significance of zero space vector placement for carrier based PWM schemes," in Conf. Rec. IEEE-IAS Annu. Meeting, 1995, pp. 2451-2458.

[16] S. Bhattacharya, D. G. Holmes, and D. M. Divan, "Optimizing three phase current regulators for low inductance loads," in Conf. Rec. IEEEIAS Annu. Meeting, 1995, pp. 2357-2364.

[17] L. M. Tolbert, F. Z. Peng, and T. G. Habetler, "Multilevel converters for large electric drives," IEEE Trans. Ind. Applicat., vol. 35, pp. 36-44, Jan./Feb. 1999.

[18] L. M. Tolbert, F. Z. Peng, and T. G. Habetler, "Multilevel PWM methods at low modulation indices," in Proc. IEEE APEC'99, 1999, pp. 1032-1039.

Leon M. Tolbert (S'88-M'91-SM'98), for a photograph and biography, see p. 44 of the January/February 1999 issue of this TRANSACTIONS.

Thomas G. Habetler (S'83-M'83-SM'92), for a photograph and biography, see p. 44 of the January/February 1999 issue of this TRANSACTIONS. 